HIDAKA et al.

1 Intraoperative portal venous pressure and long-term outcome of curative resection

\title{
2 for hepatocellular carcinoma
}

3

4 Masaaki Hidaka, MD, PhD, Mitsuhisa Takatsuki, MD, PhD, Akihiko Soyama, MD,

5 PhD, Takayuki Tanaka, MD, Izumi Muraoka, MD, Takanobu Hara, MD, Tamotsu

6 Kuroki, MD, PhD, Takashi Kanematsu, MD, PhD, Susumu Eguchi, MD, PhD,

7 Department of Surgery, Nagasaki University Graduate School of Biomedical Sciences,

8 Nagasaki, Japan

9

Address correspondence and Reprint requests to:

Susumu Eguchi, M.D. Ph.D.

Department of Surgery, Nagasaki University Graduate School of Biomedical

Sciences, 1-7-1 Sakamoto, Nagasaki, Japan

Tel: +81-95-819-7316, FAX: +81-95-819-7319

e-mail: sueguchi@nagasaki-u.ac.jp

Original article, financial support: No grants and other financial support

Running head: Influence of portal pressure on hepatectomy for HCC

\section{Abbreviations}

HCC, hepatocellular carcinoma, ICG-R15, indocyanine green retention at 15 minutes 
HIDAKA et al.

1 LHL 15, liver to heart uptake ratio at 15 minutes

$2 \quad$ PVP, portal venous pressure

3 Key words: hepatocellular carcinoma, liver resection, portal venous pressure 


\section{ABSTRACT}

2 Background: Outcomes of liver resection for hepatocellular carcinoma (HCC) have

3 improved due to better surgical techniques and patient selection. Portal hypertension

4 may influence outcome but the preoperative definition and role of portal hypertension

5 are far from clear. The aim of this study was to elucidate the influence of intraoperative

6 directly measured portal venous pressure (PVP) on outcomes of liver resection in

7 patients with HCC.

8 Methods: Patients who underwent resection of their HCC between 1997 and 2009 and

9 who underwent direct measurement of PVP immediately after laparotomy were enrolled.

10 These patients were divided into two groups according to PVP; PVP $\geq 20 \mathrm{cmH}_{2} \mathrm{O}$ (high

11 PVP group) or PVP $<20 \mathrm{cmH}_{2} \mathrm{O}$ (low PVP group). The influence of PVP on survival

12 rates and recurrence free survival rates was analyzed and prognostic factors were

13 identified.

14 Results: A total of 177 patients were enrolled, 129 in low PVP group and 48 in high

15 PVP group. The 5-year survival rate and recurrence free survival rate were significantly

16 higher in patients with low PVP 63.7\% vs. 31.4\%, $(\mathrm{P}<0.001)$ and $52.5 \%$ vs. $12.1 \%$ (P

$17<0.001$ ), respectively. In multivariate analysis, tumor number $\geq 2$, tumor diameter $\geq 5 \mathrm{~cm}$,

18 high PVP, liver damage of class B, hepatic activity index (HAI) grading 7 and AFP 
HIDAKA et al.

$1 \geq 100 \mathrm{ng} / \mathrm{ml}$ were significant predictors of poorer survival after liver resection. Tumor

2 number $\geq 2$, tumor diameter $\geq 5 \mathrm{~cm}$ and HAI grading $\geq 7$ were significant predictors of a

3 poorer recurrence.

4 Conclusion: Portal venous pressure is associated with the long term outcome of liver

5 resection for HCC. 


\section{INTRODUCTION}

2

3

4

5

6

7

9 in patients with liver cirrhosis (LC). Patients with LC often have portal hypertension preoperatively, and currently are not candidates for liver resection, especially major hepatectomy, according to USA and European guidelines $(5,6)$. Several reports have

12 shown that the preoperatively estimated portal hypertension was associated with the prognosis of $\operatorname{HCC}(7,8)$. Major hepatic resection increases portal venous pressure

14 (PVP) in cirrhotic and non-cirrhotic livers, this increase in PVP after hepatectomy however does not seem to have a direct effect on early postoperative morbidity and mortality (10). On the other hand, directly measured high PVP during hepatectomy was associated with complications after hepatectomy in cirrhotic patients with HCC (11). 
HIDAKA et al.

1 patients with HCC after hepatic resection and to identify factors affecting recurrence

2 and survival.

3

4 METHODS

5 Patients

6

All patients with HCC, who underwent curative hepatic resection between

7 January 1997 and December 2009 in the Department of Surgery, Nagasaki University

8 Hospital and in whom PVP was measured were eligible for the study. Curative resection

9 was defined as an operation in which all tumors were macroscopically resected during

10 surgery. Hepatic resection was performed based on preoperative tumor staging and liver

11 function tests. The selection for minor resection (partial hepatectomy or segmentectomy) or major resection (bisegmentectomy and lobectomy) was based on the

13 location and diameter of HCC and liver function test (10). Tumor staging included

14 preoperative ultrasonography (US), multidetector computed tomography (MDCT), and magnetic resonance imaging (MRI) in all patients. Preoperative liver function was

16 assessed by liver function tests, indocyanine green retention for 15 minutes (ICG-R15),

17 liver scintigraphy represented by liver to liver plus heart ratio at 15 minutes after 99mTc

18 Galactosyl sialyl albumin (GSA) loading (LHL15) and Child-Pugh classification. 
1 Patient data collected before surgery included age, sex, virus status, platelet count

$2\left(\mathrm{x} 10^{4} / \mathrm{mm}^{3}\right)$, prothrombin time (PT) (\%), albumin (g/dL), total bilirubin $(\mathrm{mg} / \mathrm{dL})$,

3 alanine aminotransferase(ALT) (IU/L), Child-Pugh class, liver damage defined by Liver

4 Cancer Study Group of Japan (LCSGJ)(12), ICG R15 and LHL15.

Intra-operative PVP measurement was performed as described previously (10,

6 11). Briefly, a catheter was inserted into a jejunal mesenteric vein around $100 \mathrm{~cm}$ to

$7 \quad$ 120cm from Treitz's ligament before liver mobilization and resection. PVP was then

8 measured using a water pressure gauge with saline. Patients with a history of upper

9 abdominal surgery and mesenteric membrane adhesions were excluded because

10 intubation could not be done easily after laparotomy. A high PVP was defined as

11 pressure $\geq 20 \mathrm{cmH}_{2} \mathrm{O}(10,11)$. Pressure over $15 \mathrm{mmHg}$ was considered an indicator to

12 avoid small for size graft syndrome after liver transplantation. Generally, A PVP of 15

$13 \mathrm{mmHg}$ was taken to be equal to $20 \mathrm{cmH}_{2} \mathrm{O}$ (conversion factor 1.36) (13). Patients were

14 divided a high PVP group $\left(\geq 20.0 \mathrm{~cm} \mathrm{H}_{2} \mathrm{O}\right)$ and a low PVP group $\left(<20.0 \mathrm{cmH}_{2} \mathrm{O}\right)$ at the

15 time of the operation. Liver dysfunction was defined as patients with hyper

16 bilirubinemia, severe ascites, lower prothrombin time, and elevated sustained liver

17 functional test after hepatectomy. 
1 protein induced by vitamin K absence II (PIVKA-II) levels, and US, CT or MRI every 2

2 or 3 months. If indicated, chest CT or bone scintigraphy were performed. If tumor

3 recurrence was found, the optimal treatment (transarterial chemoembolization for

4 intrahepatic multiple recurrence, radio frequency ablation for single small recurrence,

5 repeat hepatectomy for single intrahepatic recurrence) was selected for patients with

6 preserved liver function.

\section{$8 \quad$ Analyses and Statistics}

including age, sex, virus status, Child-Pugh classification, liver damages, ICG R15,

11 LHL15, platelet count $\left(\mathrm{x} 10^{4} / \mathrm{mm}^{3}\right)$, prothrombin time (\%), serum albumin (g/dL), total and pathological data including tumor number and diameter, vascular invasion, liver

14 inflammation and fibrosis using the hepatic activity index (HAI) (14). Clinical and pathological factors related to the presence of high PVP were compared by

16 Mann-Whitney U test and Chi square test. Survival was analyzed from day of surgery to

17 most recent follow-up. Recurrence after surgery was determined by the image study.

18 Survival and recurrence free survival rates between high PVP and low PVP were 
1 assessed with the Kaplan-Meier method using the log-rank test. To clarify the

2 prognostic factors for survival and recurrence, 14 clinical and pathological variables

3 were determined. Factors on liver function included platelet count, Child-Pugh

4 classification, liver damage, ICG R15. Tumor factors included AFP level, PIVKAII

5 levels, maximum tumor size, number of tumor, type of resection, vascular invasion,

6 HAI grading and staging. Univariate and multivariable analyses of prognostic factors

$7 \quad$ were performed using the Cox proportional hazard model. Differences were considered

8 statistically significant when the p-values were $<0.05$. Statistical analyses were done

9 using SPSS Version 18.0 software package (Tokyo, Japan).

11 RESULTS

\section{Patient characteristics and differences between high and low PVP}

Eighty-three percent of patients were male, and median age was 65 (20-81).

Forty-seven patients (26.6\%) were seropositive for hepatitis B antigen (HBs-Ag), three seropositive for HCV and 43 (24.3\%) were seronegative for both HBs-Ag and HCV-Ab. There were 48 patients with high PVP and 129 patients with low PVP. The 
1 the parameters related to the PVP, are described in Table 1. Patients with a high PVP

2 had a lower platelet count, a lower PT, lower albumin, higher ALT, higher CP class,

3 higher liver damage class, higher ICG R15, lower LHL15, higher AFP level, and less

4 frequent solitary tumors, resulting in fewer major hepatectomies, and a higher hepatic

5 activity index (HAI) grading and staging. Eighteen patients had less than $10 \times 10^{4} / \mathrm{mm}^{3}$

6 platelets in the high PVP group (27.1\%) and 13 (10\%) in the low PVP group. Twenty

7 patients (41.6\%) in the high PVP group developed complications after hepatectomy,

8 including ascites in 8 (16.6\%), pleural effusion in 8 (16.6\%), and infectious disease in 8

9 (16.6\%) patients. Fifty-four patients (41.9\%) with low PVP developed complications,

10 with ascites in 18 (13.9\%), pleural effusion in 23 (17.8\%), and infectious disease in 9

11 (7\%) respectively. There were no differences in postoperative incidence of the pleural

12 effusion, ascites, and infection between the high and low PVP groups. However,

13 patients with a high PVP had significantly more often liver dysfunction $(n=7)$ compared

14 to the low PVP group $(\mathrm{n}=2, \mathrm{p}=0.01)$.

\section{Patient survival and recurrence free survival}

18 due to liver failure and sepsis with multi-organ failure after hepatectomy. Recurrence 
1 after resection developed in 37 patients (77.0\%) in the high PVP group, and in 93

2 patients (72.1\%) in the low PVP group. The one, 3- and 5-year survival rates of the

3 low PVP group ( $\mathrm{n}=129)$ were $92.0 \%, 78.2 \%$ and $63.7 \%$, respectively. This was

4 significantly better than the corresponding $72.9 \%$, $48.5 \%$ and $31.4 \%$ survival rates in

5 the high PVP group $(\mathrm{n}=48)(\mathrm{p}<0.001)$ Figure 1. The 1-year, 3-year and 5-year

6 recurrence free survival rates of the low PVP group were 73.9\%, 61.0\% and 52.5\%,

7 respectively. This again was significantly better than the corresponding $47.7 \%, 27.0 \%$

8 and $12.1 \%$, respectively in the high PVP group $(\mathrm{p}<0.001)$ Figure 2.

Prognostic factors for survival and recurrence free survival

Univariate analysis identified 7 significant prognostic factors for survival in patients with high PVP. The presence of multiple tumors, tumor diameter $\geq 5 \mathrm{~cm}$, high PVP, liver damage class B, HAI grading $\geq 7$, AFP $\geq 100 \mathrm{ng} / \mathrm{ml}$, and vascular invasion were significant prognostic factors for poorer survival (Table 2). identified as significant in the univariate analysis. Presence of multiple tumors, tumor diameter $\geq 5 \mathrm{~cm}$, high PVP, liver damage, and a HAI grading $\geq 7$ were identified as independent prognostic indicators for survival. 
HIDAKA et al.

1

2

3

4

5

6 7

(

Table 3 shows the results of the univariate analysis to identify factors related to

recurrence. Poor prognostic factors were the presence of multiple tumors, tumor diameter $\geq 5 \mathrm{~cm}$, an HAI grading $\geq 7$, high PVP, vascular invasion, and AFP $\geq 100 \mathrm{ng} / \mathrm{ml}$. The presence of multiple tumors, tumor diameter $\geq 5 \mathrm{~cm}$, and an HAI grading $\geq 7$ were identified as significant prognostic indicators for recurrence based in the multivariable analysis.

\section{DISCUSSION}

Portal hypertension is considered to be a contraindication for liver resection according the EASL/AASLD guidelines $(5,6)$. However, in recent years liver resection for cirrhotic patients has been performed safely. According to these guideline, treatment for such patients with HCC should be local therapy, such as radio frequency ablation (RFA) or transarterial chemoembolization (TACE). Bruix et al. reported that a hepatic venous pressure gradient $\geq 10 \mathrm{mmHg}$ was the most powerful predictor of postoperative liver failure in cirrhotic patients (7). Caupussoti et al. observed that survival was worse in patients with portal hypertension than in patients without portal hypertension, although the results were similar for patients with or without portal hypertension if only patients with Child-Pugh A disease were evaluated (9). On the other hand, Imamura et 
HIDAKA et al.

1 al. analyzed 1056 consecutive liver resections (532 for HCC, 262 for other liver

2 malignancies, 57 for biliary tract malignancy, 174 living donor and 31 for other disease)

3 that did not result in mortality over a period of 8 years. They concluded that portal

4 hypertension and liver cirrhosis did not affect overall postoperative complications in

5 patients with HCC, and identified blood loss greater than or equal to $1000 \mathrm{~mL}$ as the

6 major risk factor (3).

8 cirrhotic patients divided in 2 groups according to the presence or absence of portal

9 hypertension. They identified the preoperative MELD score as the major determinant of

10 postoperative outcome. Portal hypertension in this analysis did not affect postoperative

11 complication rates in patients with HCC (15).

The present study demonstrated that a high PVP is related to of liver inflammation and fibrosis as evidenced by the incidence of lower platelets, PT, albumin,

14 a higher Child Pugh score, HAI grading and staging. Partial hepatectomies or segmentectomies, i.e. limited hepatic resections of the liver, were deemed appropriate

16 more often for patients with a high PVP as patients with a $\mathrm{PVP} \geq 20 \mathrm{~cm} \mathrm{H}_{2} \mathrm{O}$ are more

17 likely to develop hyperbilirubinemia after hepatectomy (11). Limited resections for

18 patients with liver cirrhosis proved to be an effective treatment for HCC to avoid liver 
HIDAKA et al.

1 dysfunction and mortality after hepatectomy in the author's unit (16).

2

3

4

5

6 from the cut-off values of PVP that were used in the different studies. The BCLC group

7 labeled patients as having hypertension based on the presence of esophageal varices, 8 splenomegaly and a platelet count $<100,000 / \mathrm{mm}^{3}$. This differs markedly from the direct

HCC in patients with severe cirrhosis can arise anywhere in the cirrhotic liver as multicentric occurrence carcinogenesis. Minute and 'undetectable' HCC may be found in explant livers in patients with severe cirrhosis at liver transplantation (17). The differences between the present data and those of other reports may have resulted measurement of portal vein pressure during surgery (7). Figueras reported that portal vein pressure at the beginning of surgery, hepatic venous pressure gradient (HVPG), high central venous pressure (CVP), and intraoperative blood loss were factors associated with complications after liver resection (18). In the current authors' indication CVP before liver resection was usually $5 \mathrm{mmHg}$, and it was assumed that a PVP of $20 \mathrm{cmH}_{2} \mathrm{O}$ before liver resection would be equivalent to a PVP of $15 \mathrm{mmHg}$ and an HVPG of 10mmHg (HVPG = PVP - CVP). However detailed data concerning the CVP at the start of surgery in this study were not available.

Capussotti et al. showed that the presence of portal hypertension in patients with Child Pugh-A did not affect overall survival (9). Ripoll et al. showed that portal 
1 hypertension, assessed via a hepatic venous pressure gradient, was an independent

2 predictor of survival of patients (8). The present data support these results indicating

3 that overall survival and recurrence free survival rates after hepatectomy were worse in

4 patients with high PVP (assessed by direct portal venous pressure) $>20 \mathrm{~cm} \mathrm{H}_{2} \mathrm{O}$. In this

5 study, overall survival was lower in patients with high PVP because of their worse liver

6 function. A high PVP may reflect inflammation and fibrosis in the liver, and may be

7 associated with liver dysfunction because HAI grading of the background liver and

8 staging was worse in the high PVP group than in the low PVP group. A multivariable

9 analysis for recurrence revealed that the presence of multiple and huge tumors, and

10 inflammation in the remnant liver, were associated with earlier recurrence of HCC after

11 hepatectomy even after curative resection. Indeed high PVP was not associated with

12 recurrence although RFS in high PVP group was significantly inferior to that in the low

13 PVP group. High PVP was the fourth harvest associated with recurrence followed by

14 high HAI Grading. High PVP may have the potential inflammation in the remnant liver

15 and reflect the impaired liver function which caused to the potential multi-centric

16 carcinogenesis in the liver. HPVG measurement allows selection of patients pre-operatively and therefore,

18 this may be more appropriate in the future. 
HIDAKA et al.

2 Author Contributions

3 Study conception and design: Hidaka, Eguchi

4 Acquisition of data: Tanaka, Muraoka, Hara

$5 \quad$ Analysis and interpretation of data: Takatsuki, Soyama, Kuroki

6 Drafting of manuscript: Hidaka, Eguchi, Kanematsu

$7 \quad$ Critical revision: Kanematsu, Eguchi

8 Acknowledgment: The authors wish to thank our colleagues in the Department of

9 Surgery, Graduate School of Biomedical Sciences, Nagasaki University, for their kind 10 cooperation and support. 


\section{References}

2 1. Yang JD, Robert LR. Hepatocellular carcinoma: A global view. Nat Rev Gastroenterol Hepatol 2010; 7: 448-458.

2. Poon RT, Fan ST, Lo CM, Liu CL, Lam CM, Yuen WK, et al. Improving perioperative outcome expands the role of hepatectomy in management of benign and malignant hepatobiliary diseases: analysis of 1222 consecutive patients from a prospective database. Ann Surg. 2004; 240: 698-708.

8 3. Imamura H, Seyama Y, Kokudo N, Maema A, Sugawara Y, Sano K, et al. One thousand fifty-six hepatectomies without mortality in 8 years. Arch Surg. 2003; 138: $1198-1206$.

4. Teh SH, Christein J, Donohue J, Que F, Kendrick M, Farnell M, et al. Hepatic resection of hepatocellular carcinoma in patients with cirrhosis: Model of End-Stage Liver Disease (MELD) score predicts perioperative mortality. $J$ Gastrointest Surg. 2005; 9: 1207-1215.

5. Bruix J, Sherman M. Management of hepatocellular carcinoma. AASLD practice guideline. Hepatology 2005; 42: 1208-1236. 
1 conclusions of the Barcelona-2000 EASL conference. European Association for the

$2 \quad$ Study of the Liver. J Hepatol. 2001; 35: 421-430.

3 7. Bruix J, Castells A, Bosch J, Feu F, Fuster J, Garcia-Pagan JC, et al. Surgical resection of hepatocellular carcinoma in cirrhotic patients; prognostic value of preoperative portal pressure. Gastroentetology 1996; 111: 1018-1022.

8. Ripoll C. Hepatic venous pressure gradient and outcomes in cirrhosis. J Clin Gastroenterol. 2007; 41: S330-S335.

9. Capussotti L, Ferrero A, Viganò L, Muratore A, Polastri R, Bouzari H. Portal hepertension : Contraindication to liver surgery ? World J Surg. 2006; 30: 992-999.

10. Kanematsu T, Furui J, Yanaga K, Okudaira S, Kamohara Y, Eguchi S. Measurement of portal venous pressure is useful for selecting the optimal type of resection in cirrhotic patients with hepatocellular carcinoma. Hepatogastroenterology. 2005; 52: 1828-1831.

11. Kanematsu T, Takenaka K, Furuta T, Ezaki T, Sugimachi K, Inokuchi K. Acute portal hypertension associated with liver resection. Analysis of early postoperative death. Arch Surg. 1985; 120: 1303-1305. 
1

2010; 1-110.

13. Ogura Y, Hori T, El Moghazy WM, Yoshizawa A, Oike F, Mori A, et al. Portal pressure $<15 \mathrm{~mm} \mathrm{Hg}$ is a key for successful adult living donor liver transplantation utilizing smaller grafts than before. Liver transpl. 2010; 16: 718-728.

14. Ishak K, Baptista A, Bianchi L, Callea F, De Groote J, Gudat F, et al. Histological grading and staging of chronic hepatitis. J Hepatol. 1995; 22: 696-699.

15. Cucchetti A, Ercolani G, Vivarelli M, Cescon M, Ravaioli M, Ramacciato G, et al. Is portal hypertension a contraindication to hepatic resection? Ann Surg. 2009; 250: 922-928.

16. Kanematsu T, Takenaka K, Matsumata T, Furuta T, Sugimachi K, Inokuchi K. Limited hepatic resection effective for selected cirrhotic patients with primary liver cancer. Ann Surg. 1984; 199: 51-56.

17. Hidaka M, Eguchi S, Okudaira S, Takatsuki M, Tokai H, Soyama A, et al. Multicentric occurrence and spread of hepatocellular carcinoma in whole explanted end-stage liver. Hepatol Res. 2009; 39: 143-148.

18. Figueras J, Llado L, Ruiz D, Ramos E, Busquets J, Rafecas A, et al. Complete vesus selective portal triad clamping for minor liver resections: a prospective randomized trial. Ann Surg 2005; 241: 582-590. 


\section{Figure legends}

2 Figure 1. Comparison of survival in patients with an HCC and high PVP or low PVP

3 after hepatectomy $(\mathrm{p}<0.001)$. PVP, portal venous pressure

5 Figure 2. Comparison of the recurrence free survival in patients with an HCC and

6 high PVP or low PVP after hepatectomy ( $\mathrm{p}<0.001)$. PVP, portal venous pressure

8 Table 1. Clinical characteristics of patients with high or low PVP under going

9 hepatectomy for HCC

10 AFP, alpha-fetoprotein; ALT, alanine aminotransferase; HAI, hepatic activity index;

11 ICG R15, indocyanine green retention test at 15 minutes; LHL, liver to liver plus heart

12 uptake ratio at 15 minutes; PIVKA II, protein induced by vitamin K absence II.

14 Table 2. Results of univariate and multivariable analyses of prognostic factors

15 regarding survival after hepatectomy

16 AFP, alpha-fetoprotein; ICG R15, indocyanine green retention test at 15 minutes; LHL,

17 liver to liver plus heart uptake ratio at 15 minutes; PIVKA II, protein induced by

18 vitamin K absence II; PVP, portal venous pressure. 
HIDAKA et al.

1

2 Table 3. Results of the univariate and multivariable analyses of prognostic factors

3 regarding recurrence after hepatectomy

4 AFP, alpha-fetoprotein; ICG R15, indocyanine green retention test at 15 minutes; LHL,

5 liver to liver plus heart uptake ratio at 15 minutes; PIVKA II, protein induced by

6 vitamin K absence II; PVP, portal venous pressure.

7 


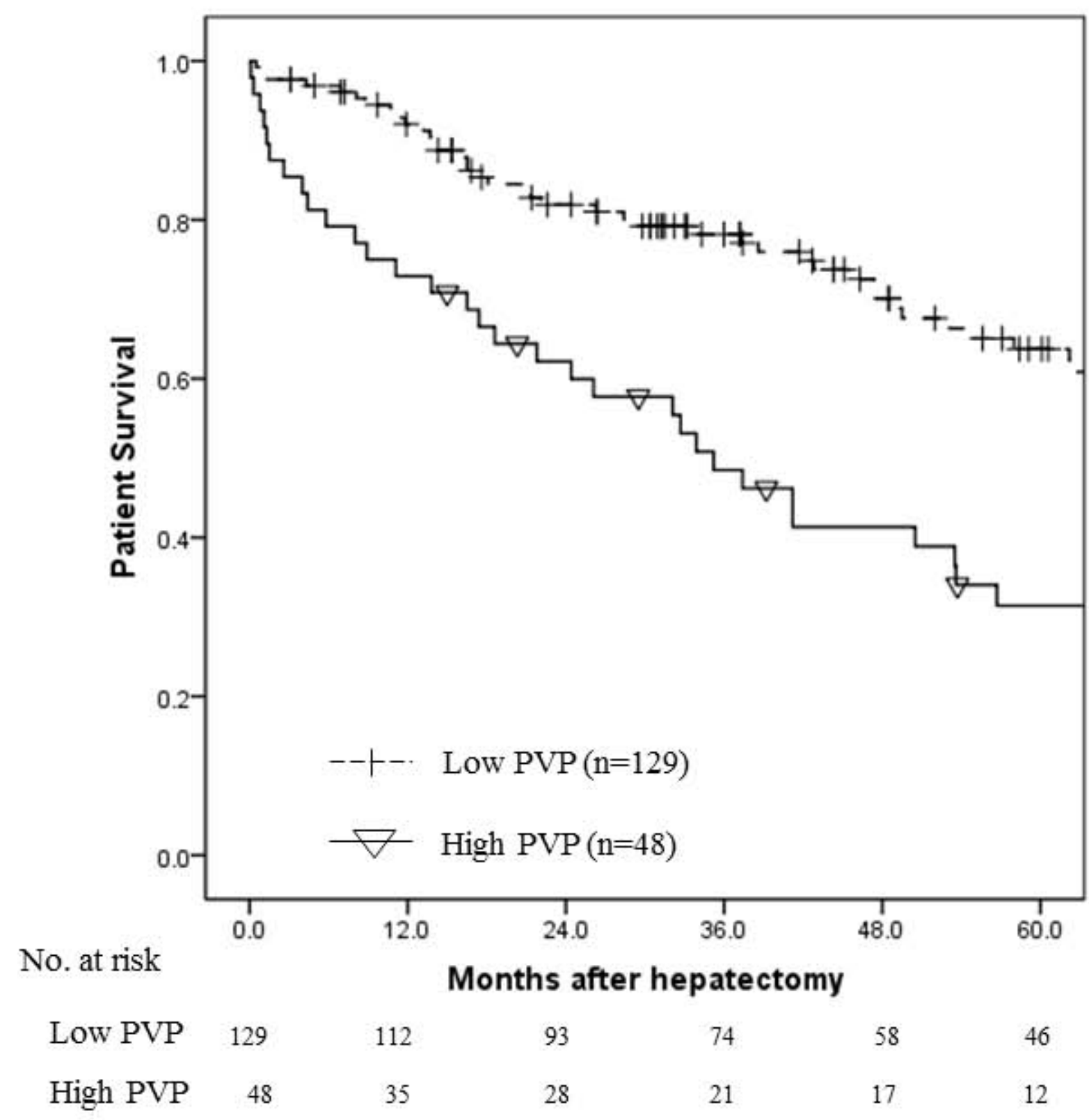

Figure 1. Comparison of survival in patients with an HCC and high PVP or low PVP after hepatectomy $(p<0.001)$. 


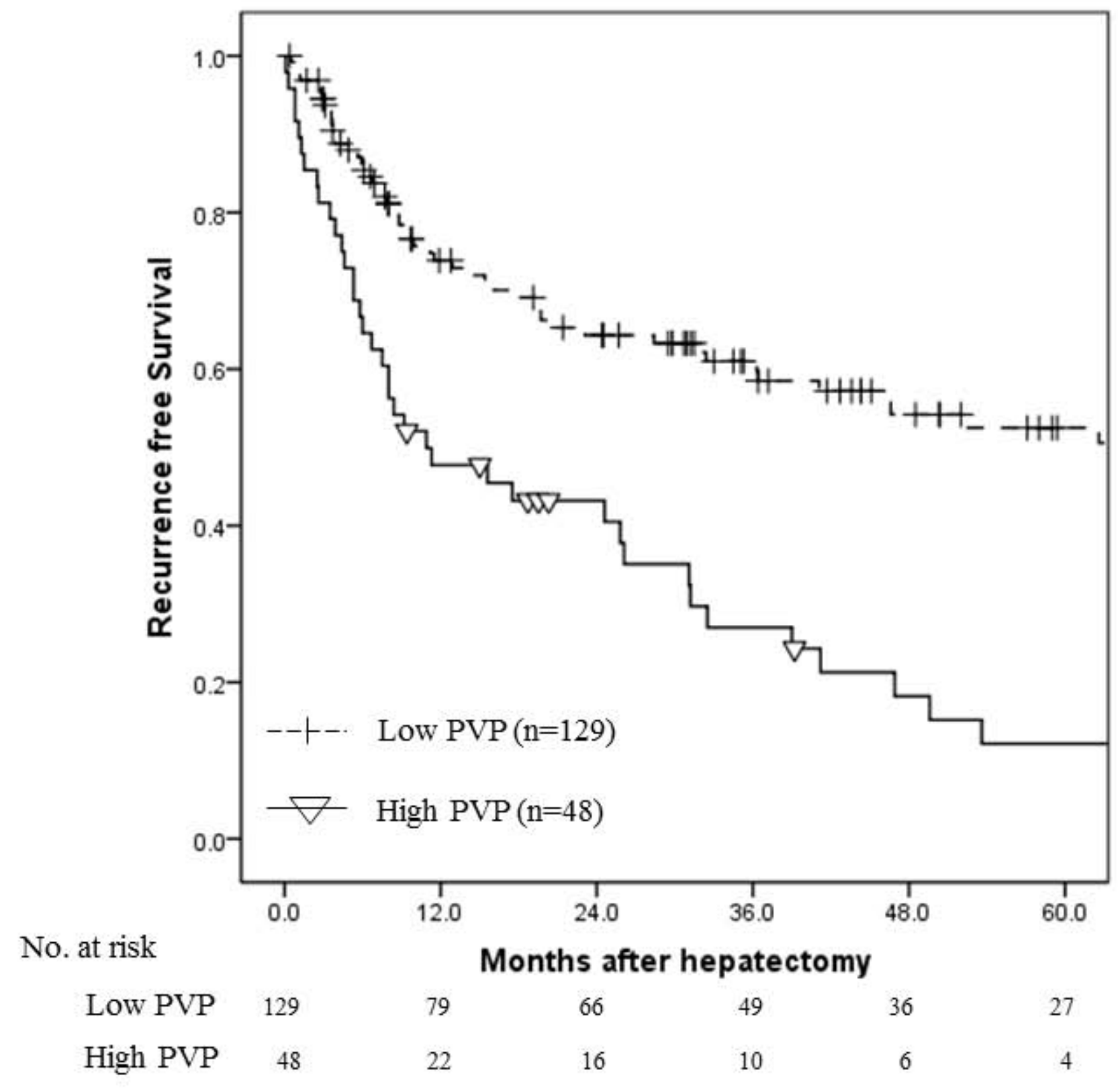

Figure 2. Comparison of the recurrence free survival in patients with an $\mathrm{HCC}$ and high PVP or low PVP after hepatectomy $(\mathrm{p}<0.001$ ). 


\begin{tabular}{|c|c|c|c|}
\hline Variables & $\begin{array}{c}\text { High PVP } \\
\left(\geq 20 \mathrm{cmH}_{2} \mathrm{O}\right) \\
(\mathrm{n}=48)\end{array}$ & $\begin{array}{c}\text { Low PVP } \\
\left(<20 \mathrm{cmH}_{2} \mathrm{O}\right) \\
(\mathrm{n}=129)\end{array}$ & p-value \\
\hline Ages (years) & $63(43-78)$ & $66(20-81)$ & 0.162 \\
\hline $\operatorname{Sex}(M: F)$ & $40: 8$ & $107: 22$ & 0.856 \\
\hline Etiology & & & 0.347 \\
\hline Hepatitis B & $14(29.2 \%)$ & $33(25.6 \%)$ & \\
\hline Hepatitis C & 26 (54.2\%) & $58(45.0 \%)$ & \\
\hline Hepatitis B + C & $1(2.0 \%)$ & $2(1.5 \%)$ & \\
\hline Negative & 7 (14.6\%) & 36 (27.9\%) & \\
\hline Platelet count (x104/mm³) & $11.8(4.1-35.6)$ & $15.9(2.6-47)$ & 0.001 \\
\hline Prothrombin time (\%) & $83.7(63-105)$ & $91(54-122)$ & 0.002 \\
\hline Albumin (g/dl) & $3.8(2.5-4.7)$ & $4.0(2.8-4.8)$ & 0.001 \\
\hline Total bilirubin (mg/dl) & $0.9(0.4-4.8)$ & $0.7(0.3-2.4)$ & 0.06 \\
\hline ALT (IU/L) & $55.5(18-190)$ & $34.5(7-222)$ & 0.002 \\
\hline Child Pugh classification & & & 0.004 \\
\hline Class A & 38 (79.2\%) & 122 (94.6\%) & \\
\hline Class B & $10(20.8 \%)$ & $7(5.4 \%)$ & \\
\hline Liver damage & & & 0.001 \\
\hline Class A & 30 (62.5\%) & 109 (76.8\%) & \\
\hline Class B & $18(37.5 \%)$ & 17 (13.2\%) & \\
\hline ICG R15 (\%) & $18(3-39)$ & $11(1-40)$ & 0.004 \\
\hline LHL15 & $0.89(0.77-0.96)$ & $0.93(0.61-0.97)$ & 0.001 \\
\hline AFP (ng/ml) & $47.5(4.2-454,300)$ & $13.1(1.2-151,367)$ & 0.03 \\
\hline PIVKAII (mAU/ml) & $73(21$ - 10,173) & $133(2-60,380)$ & 0.52 \\
\hline Tumor diameter (cm) & $2.9(1.0-13.0)$ & $4.0(0.5-17.0)$ & 0.08 \\
\hline Solitary tumor & 29 (59.1\%) & $101(78.3 \%)$ & 0.01 \\
\hline \multicolumn{4}{|l|}{ Type of hepatectomy } \\
\hline Minor hepatectomy & 41 (85.4\%) & 76 (58.9\%) & 0.001 \\
\hline Major hepatectomy & $7(14.6 \%)$ & $53(31.1 \%)$ & \\
\hline Vascular invasion & $10(26.3 \%)$ & 40 (31.9\%) & 0.207 \\
\hline \multicolumn{4}{|l|}{ HAI } \\
\hline Grading & $9.1(3-13)$ & $4.8(1-13)$ & 0.001 \\
\hline Staging & $3.8(2-4)$ & $2.1(0-4)$ & 0.001 \\
\hline
\end{tabular}

Table 1. Clinical characteristics of patients with high or low PVP under going hepatectomy for HCC 


\begin{tabular}{|c|c|c|c|c|c|c|c|}
\hline \multirow[b]{2}{*}{ Variables } & \multirow[b]{2}{*}{ Category } & \multicolumn{3}{|c|}{ Univariate analysis } & \multicolumn{3}{|c|}{ Multivariable analysis } \\
\hline & & Hazard ratio & $95 \% \mathrm{CI}$ & $\mathrm{p}$-value & Hazard ratio & $95 \% \mathrm{CI}$ & $\mathrm{p}$-value \\
\hline Tumor number & $\geq 2$ & 3.15 & $2.02-4.90$ & $<0.001$ & 2.52 & $1.58-4.02$ & $<0.001$ \\
\hline Tumor diameter $(\mathrm{cm})$ & $\geq 5$ & 1.67 & $1.09-2.54$ & 0.018 & 2.22 & $1.41-3.50$ & 0.001 \\
\hline PVP & $\geq 20 \mathrm{cmH}_{2} \mathrm{O}$ & 2.44 & $1.60-3.60$ & $<0.001$ & 1.74 & $1.24-3.03$ & 0.004 \\
\hline Liver damage & $\mathrm{B}$ & 1.91 & $1.19-3.07$ & 0.007 & 1.74 & $1.07-2.82$ & 0.026 \\
\hline HAI Grading & $\geq 7$ & 2.14 & $1.42-3.25$ & $<0.001$ & 1.65 & $1.04-2.63$ & 0.034 \\
\hline AFP (ng/ml) & $\geq 100$ & 1.69 & $1.11-2.57$ & 0.013 & & & 0.354 \\
\hline Vascular invasion & + & 1.68 & $1.08-2.61$ & 0.02 & & & 0.521 \\
\hline Platelet count $\left(\mathrm{x} 10^{4} / \mathrm{mm}^{3}\right)$ & $\leq 10$ & 0.99 & $0.60-1.63$ & 0.985 & & & \\
\hline ICG R15 (\%) & $\geq 15$ & 1.21 & $0.81-1.80$ & 0.354 & & & \\
\hline LHL 15 & $\leq 0.9$ & 0.6 & $0.34-1.07$ & 0.79 & & & \\
\hline PIVKA II & $\geq 100$ & 0.85 & $0.53-1.37$ & 0.515 & & & \\
\hline Child Pugh & B & 1.49 & $0.83-2.70$ & 0.177 & & & \\
\hline Partial hepatectomy & + & 1.17 & $0.77-1.76$ & 0.465 & & & \\
\hline HAI Staging & 4 & 1.31 & $0.84-2.03$ & 0.24 & & & \\
\hline
\end{tabular}


Table 2. Results of univariate and multivariable analyses of prognostic factors regarding survival after hepatectomy

AFP, alpha-fetoprotein; HAI, hepatic activity index; ICG R15, indocyanine green retention test at 15 minutes; LHL, liver to liver plus heart uptake ratio at 15 minutes; PIVKA II, protein induced by vitamin K absence II; PVP, portal venous pressure. 
Univariate analysis

\begin{tabular}{|c|c|c|c|c|c|c|c|}
\hline & & & & & & & \\
\hline Variables & Category & Hazard ratio & $95 \% \mathrm{CI}$ & p-value & Hazard ratio & $95 \% \mathrm{CI}$ & p-value \\
\hline Tumor number & $\geq 2$ & 2.49 & $1.68-3.69$ & $<0.001$ & 2.3 & $1.49-3.54$ & $<0.001$ \\
\hline Tumor diameter (cm) & $\geq 5$ & 1.86 & $1.27-2.72$ & 0.001 & 2.19 & $1.39-3.17$ & $<0.001$ \\
\hline HAI Grading & $\geq 7$ & 1.77 & $1.21-2.57$ & 0.003 & 1.72 & $1.16-2.56$ & 0.007 \\
\hline PVP & $\geq 20 \mathrm{cmH}_{2} \mathrm{O}$ & 1.65 & $1.10-2.48$ & 0.014 & & & 0.328 \\
\hline Vascular invasion & + & 1.65 & $1.10-2.48$ & 0.015 & & & 0.479 \\
\hline AFP (ng/ml) & $\geq 100$ & 1.49 & $1.01-2.23$ & 0.047 & & & 0.189 \\
\hline Platelet count $\left(\mathrm{x} 10^{4} / \mathrm{mm}^{3}\right)$ & $\leq 10$ & 1.04 & $0.66-1.65$ & 0.854 & & & \\
\hline ICG R15 (\%) & $\geq 15$ & 1.3 & $0.94-1.96$ & 0.1 & & & \\
\hline LHL 15 & $\leq 0.9$ & 0.74 & $0.48-1.17$ & 0.195 & & & \\
\hline PIVKA II & $\geq 100$ & 1.39 & $0.95-2.03$ & 0.085 & & & \\
\hline
\end{tabular}




$\begin{array}{lcccc}\text { Child Pugh } & \text { B } & 1.09 & 0.60-1.98 & 0.775 \\ \text { Liver damage } & \text { B } & 1.36 & 0.87-2.13 & 0.167 \\ & & & & \\ \text { Partial hepatectomy } & + & 1.08 & 0.74-1.57 & 0.704 \\ \text { HAI Staging } & 4 & 1.01 & 0.66-1.55 & 0.957\end{array}$

Table 3. Results of the univariate and multivariable analyses of prognostic factors regarding recurrence after hepatectomy

AFP, alpha-fetoprotein; HAI, hepatic activity index; ICG R15, indocyanine green retention test at 15 minutes; LHL, liver to liver plus heart uptake ratio at 15 minutes; PIVKA II, protein induced by vitamin K absence II; PVP, portal venous pressure. 